\title{
FRONTEIRAS COLETIVAS E REPERTÓRIOS ETNORRACIAIS NO BRASIL CONTEMPORÂNEO
}

\author{
Nuno Oliveira \\ Instituto Universitário de Lisboa (ISCTE-IUL), Centro de Investigação e Estudos de Sociologia \\ (CIES-IUL), Lisboa, Portugal
}

Resumo O artigo argumenta que a política étnica no Brasil mudou para conceções mais assertivas da pertença grupal. Analisando a ação afirmativa para negros no Brasil contemporâneo, o artigo discute três repertórios diferenciados com implicações para a construção de fronteiras coletivas de natureza etnorracial, que designámos diluição, negociação e saliência. Tais quadros permitem organizar a perceção da diversidade étnica e racial. A importância das narrativas de identidade nacional na estruturação de tais quadros é realçada. O artigo defende ainda a necessidade de considerar o papel do estado e dos seus agentes no estabelecimento das legítimas codificações da pertença.

Palavras-chave: repertório, fronteiras, categorização, identidades coletivas, identidade nacional

Abstract The article argues that ethnic policy in Brazil has changed in such a way as to adopt more assertive concepts of group belonging. Analysing affirmative action in favour of Black people in contemporary Brazil, the article discusses three differentiated repertoires with implications for the construction of collective boundaries of an ethnoracial nature, which the author calls dilution, negotiation and salience. These frameworks make it possible to organise the perception of ethnic and racial diversity. The importance of narratives of national identity in the ways these frameworks are structured is highlighted. The article also posits the need to consider the role of the state and its agents in the establishment of the legitimate codifications of belonging.

Keywords: repertoire, boundaries, categorisation, collective identities, national identity.

Résumé Cet article soutient que la politique ethnique menée au Brésil s'est orientée vers des conceptions plus assertives de l'appartenance groupale. En analysant l'action affirmative pour les noirs dans le Brésil contemporain, l'article établit trois répertoires distincts qui ont des implications pour la construction de frontières collectives de nature ethnoraciale, désignés par dilution, négociation et prédominance, et qui permettent d'organiser la perception de la diversité ethnique et raciale. L'importance des discours sur l'identité nationale dans la structuration de ces répertoires est soulignée. L'article soutient également la nécessité de considérer le rôle de l'État et de ses agents dans l'établissement des codifications légitimes de l'appartenance.

Mots-clés: répertoire, frontières, catégorisation, identités collectives, identité nationale.

Resumen El artículo argumenta que la política étnica en Brasil mudó para concepciones más asertivas de la pertenencia grupal. Analizando la acción afirmativa para negros en Brasil contemporáneo, el artículo discute tres repertorios diferenciados con implicaciones para la construcción de fronteras colectivas de naturaleza etnoracial que designamos por dilución, negociación y destaque. Tales modelos permiten organizar la percepción de la diversidad étnica y racial. La importancia de las narrativas de identidad nacional en la estructuración de tales modelos es destacada. El artículo defiende aún la necesidad de considerar el papel del Estado y de sus agentes en el establecimiento de las legítimas codificaciones de pertenencia.

Palabras-clave: repertorio, fronteras, categorización, identidades colectivas, identidad nacional. 


\section{Introdução}

A implementação de políticas de ação afirmativa no Brasil, especialmente a adoção de quotas para negros nas universidades públicas, desencadeou um debate acirrado sobre os limites da classificação etnorracial. A controvérsia sobre a ação afirmativa baseada na raça demarcou campos na sociedade brasileira entre aqueles que argumentaram que em uma sociedade mista como o Brasil (incluindo geneticamente) tais divisões eram artificiais e outros que argumentavam que, sendo a discriminação racial um fenómeno social disseminado na sociedade brasileira, a raça era relevante para quem quer que se sentia sua vítima.

No Brasil, os registos estatísticos centrais classificam os indivíduos de acordo com uma gradação de cores - branco, pardo, preto e amarelo -, que não é totalmente coincidente com as "categorias da prática" nas relações sociais quotidianas (Loveman, 1999). Esta incompatibilidade tem sido interpretada de formas opostas: por um lado, a ideia de que os sistemas de classificação etnorracial são fluidos e inter-relacionados com outras variáveis de natureza diferente (Sansone, 1996); por outro lado, a ideia de que, apesar de fluido, este sistema tem uma tradução racializada e as categorias de cor expressam divisões racializadas quotidianas (Guimarães, 1999).

O processo de implementação das políticas de ação afirmativa, juntamente com a agitação sobre as possibilidades de classificação etnorracial, oferece um caso valioso de interpelação da construção de limites coletivos e seus princípios subjacentes de legitimação. Ou seja, de compreender as formas de estruturar expressões políticas e simbólicas que definem e redefinem as fronteiras de grupos através de classificações públicas legitimadas.

Recentemente, uma linha de pesquisa tem desenvolvido ferramentas para estudar o "fazer e desfazer" das fronteiras etnorraciais no Brasil (Silva, 2016; Silva e Reis, 2012). Embora tenham trazido algumas perceções significativas sobre como as pessoas em diferentes posições sociais compreendem a pertença etnorracial e as suas mudanças atuais, parecem ignorar as dinâmicas institucionais que reforçam, em efeitos de retroação, o papel dessas mudanças. Argumento que a abordagem das fronteiras (dos limites grupais) não deve basear-se unicamente no aspeto da categorização social. Assim, o ponto de partida deste artigo é a combinação de componentes cognitivos, traduzidos na linguagem dos repertórios culturais, com a dinâmica política da institucionalização das categorias, a fim de compreender a atual mudança das fronteiras etnorraciais no Brasil. Assim como essa relação foi de alguma forma negligenciada, também o papel do estado e sua penetração social têm sido insuficientemente explorados (Loveman, Muniz e Bailey, 2011; Bailey, Fialho e Peria, 2015; Silva, 2016). Estreitamente ligadas ao papel do estado, estão as narrativas de identidade nacional que sustentam uma certa visão da construção e coesão da sociedade brasileira. Por conseguinte, procuramos mostrar a relação que se estabelece entre estas narrativas e os quadros que as pessoas mobilizam relevando o seu papel condicionador nas estratégias de construção das fronteiras.

O presente artigo é baseado em trabalho de campo qualitativo envolvendo recolha de dados no Brasil em três períodos diferenciados: 2010, 2011 e 2015. Durante 
esses três períodos, realizámos entrevistas semiestruturadas com 25 atores privilegiados e recolhemos material documental de várias fontes. O grupo de entrevistados resultou de uma seleção anterior que levou em conta a forma como as pessoas se posicionam em configurações de poder. Desta forma, as entrevistas foram direcionadas a atores privilegiados, tais como funcionários do estado responsáveis pela institucionalização de regras e códigos, atores académicos com um papel na definição e articulação discursiva de modelos cognitivos e morais, líderes do movimento social e intermediários entre coletivos e instituições do estado. ${ }^{1}$ Todas as entrevistas foram codificadas e analisadas usando MaxQDA (v. 12), o que nos permitiu identificar, indutivamente, padrões de resposta com base na frequência do código primário. Além das entrevistas, o artigo baseia-se num corpus constituído por textos publicados em sites online, documentos da sociedade civil e instituições de autoridade pública, uma coleção de textos legais e outros materiais escritos, como blogs e artigos de jornais. Embora tal acervo não tenha sido sujeito a análise com o MaxQDA, constitui parte do material sobre o qual se refletiu e retirou inferências que consolidam as conclusões. Adicionalmente, participámos também em debates e conferências sobre a ação afirmativa e a nova configuração jurídica da concessão de direitos coletivos.

Na primeira parte, oferecemos uma revisão teórica da teoria da construção de fronteiras simbólicas, sugerindo uma maneira de vinculá-la à acomodação da diversidade etnorracial que leve em conta a imbricação entre estruturas cognitivas e formulação de políticas. Na secção seguinte, esboçamos o processo de elaboração de políticas que levou à consolidação de um quadro de ação afirmativa e à institucionalização da semântica etnorracial no Brasil. Posteriormente, salientamos a pluralidade de modalidades de construção de fronteiras etnorraciais e sua interação com narrativas coletivas através da caracterização dos repertórios retirados do corpus discursivo. Finalmente, propomos a ideia de formas diferenciadas de construção de fronteiras coletivas e como estas recorrem de maneira diferenciada aos componentes simbólicos da narrativa nacional.

\section{Fronteiras grupais, instituições e repertórios}

As atuais posições teóricas sobre etnicidade e raça assumem a superação das visões primordialistas; isto é, raça e etnia não são mais consideradas como uma segunda natureza, mas sim como construções sociais (Barth, 1969; Wallman, 1978). A abordagem construcionista tem sido aplicada com proveito para compreender as formas como os grupos negoceiam as suas classificações étnicas e os seus limites (ver, por exemplo, Song, 2003; Alba, 1990; Waters, 1990). Vertentes recentes da teoria das fronteiras oferecem uma abordagem alternativa que liga o construcionismo a configurações institucionais. Lamont e Wimmer argumentam convincentemente no sentido do estabelecimento de ligações entre fronteiras simbólicas, repertórios

1 Esta seleção é baseada na perspetiva de Campbell, na qual os atores são responsáveis por disseminar e institucionalizar ideias. Ver John L. Campbell, Institutional Change and Globalization (2004: 101). 
culturais e instituições (Lamont, 1995, 2000a; Wimmer, 2013). Lamont (2000b) insistiu que os membros das diferentes comunidades nacionais não são suscetíveis de mobilizar igualmente as mesmas ferramentas culturais para construir e avaliar os seus mundos sociais. Assim, há diferenças nacionais na disponibilidade dos sistemas sociais simbólicos que tornam certos princípios de classificação mais proeminentes em alguns contextos do que em outros.

As tradições culturais e as condições institucionais e estruturais limitam o uso de fronteiras específicas assim como os princípios que presidem à sua construção. Este ângulo analítico liga explicitamente os repertórios culturais às configurações institucionais históricas. Entender esses padrões envolve a consideração de mecanismos e recursos que influenciam o processo de elaboração das fronteiras étnicas ou raciais. Wimmer (2013) enfatiza elementos como controlo do poder num dado campo social, as combinações institucionais que fornecem incentivos para específicas configurações de fronteiras simbólicas, modos de categorização dos grupos, marcadores culturais definidores de pertenças sociais, assim como tipos de organização e mobilização política reforçadores de categorias étnicas e raciais. Tais especificações analíticas coincidem com a análise de Brubaker (2004) da dimensão cognitiva da construção dos grupos ou groupness. Ambos enfatizam a natureza estratégica das práticas de categorização e associação e como estas são constituintes das lutas pelas divisões legítimas do mundo social. Essa relação entre os níveis intersubjetivos e estruturais destaca a dimensão histórica, processual e relacional das fronteiras étnicas e apela a uma análise de fenómenos sociais como os discursos políticos, as narrativas da identidade nacional ou os repertórios públicos dos movimentos sociais. Mediante essa afinidade, é possível distinguir os tempos históricos quando, de facto, a etnicidade se torna "política étnica", de outras situações em que a fronteira étnica é irrelevante. A maneira como as identificações coletivas são reforçadas deriva da rede de interdependências, como o estado onde se inserem tais "formações" (Tilly, 1978) e as perceções dos seus membros sobre essas configurações, numa dinâmica de retroação que tanto pode fortalecer como enfraquecer a definição dos limites coletivos e os repertórios dos seus membros.

Os repertórios são importantes porque atenuam conceções unificadas da cultura, como aquelas que sustentam os modelos culturais nacionais. Além disso, o seu exame releva a diferença entre situações "estabelecidas", onde a cultura e a ação coincidem, e aquelas a partir das quais condições instáveis emergem (Swidler, 1986). Surgem assim narrativas conflituais e contraditórias e a coincidência entre um modelo cultural único e estabilizado e estratégias de ação deixa de ocorrer. Os repertórios culturais, como sistemas de significado dotados de princípios de classificação, estão inevitavelmente ligados aos contextos institucionais, e estes, por sua vez, são construídos por relações de poder. Por outras palavras, para analisar as modalidades do reconhecimento de fronteiras étnicas e raciais precisamos de entender o papel desempenhado pelas instituições e as lutas em campos institucionais (Wimmer, 2008).

Ao contrário de Lamont, no entanto, o presente artigo não enfoca as conceções e os quadros de referência das "pessoas comuns" (Lamont e Mizrachi, 2011). O poder é uma dimensão importante da agência. Considerando-se que os 
macroatores são aqueles que se assume terem maiores capacidades de estruturação, tal implica um reequacionar dos quadros mobilizados por "pessoas comuns", dado que "o acesso desigual aos meios de construção social" (Mouzelis, 2008), envolve uma hierarquização dos discursos, estratégias e visões legítimas do mundo social. Assim, num esforço para complementar o programa de Lamont, o foco deste artigo desloca-se para os "promulgadores dos modelos para a ordem social" (Eisenstadt, 2002), tais como decisores políticos, líderes comunitários, académicos e atores com responsabilidades públicas.

No que se segue, o artigo enfatiza o processo de institucionalização da categoria "negro" na esfera estatal e como isso provocou uma tensão nas narrativas nacionais de pertença, decorrente do facto de a velha narrativa tradicional, nacional, estar a ser contestada e não poder mais reivindicar a hegemonia.

\section{Institucionalização de um quadro para reinvidicações etnorraciais}

A história do Brasil insere-se num processo civilizacional mais amplo, que perspetivou a mistura étnica e racial como uma narrativa para a construção do estado-nação (Gross, 2012). A celebração da mistura étnica e racial foi, sob diferentes rótulos, crucial nestes processos em toda a América Latina durante o início do século XX: raza cósmica no México, criolismo moderno no Peru, democracia racial no Brasil, não racialismo afro-latino em Cuba e mestiçagem nacional na Colômbia. Tais ideologias foram parte dos projetos de construção nacional dos respetivos países, tendo sido utilizadas como parte simbólica dos processos de unificação nacionalistas destinados a superar as agudas diferenças de classe através de narrativas da mestiçagem. Este foi um consenso nacional-populista enraizado numa sociedade corporativa e carregado com um paternalismo tradicionalista cujo padrão se repetiu em vários países (Touraine, 1988; Linz e Stepan, 1996). No Brasil, esse consenso nacional desintegrou-se após a década de 70 do século XX. Os movimentos sociais apoiados em evidências fornecidas por investigadores da questão racial começaram a denunciar a persistência da desigualdade racial como a prova mais convincente de que, independentemente da ideologia da mistura, as assimetrias com base em classificações étnicas e raciais persistiam (Hasenbalg, 1979; Valle Silva, 1985; Wood e Carvalho, 1988). Para entender a dinâmica de reinvenção do projeto coletivo que dinamiza a sociedade brasileira atual, é necessário compreender as transformações institucionais e políticas que levaram à consolidação de políticas contra a discriminação racial. Este processo de institucionalização marca um ponto de viragem no paradigma do hibridismo onde se alicerçava a democracia racial. O novo modelo oferece à população negra um espaço de representação baseado num reconhecimento simbólico e prático da importância de pertenças grupais como critério para a obtenção de direitos. Em simultâneo, reformula a narrativa da identidade nacional tradicional criticando a premissa da harmonia social. Isso é parte do que Loveman (2014) identifica em toda a América Latina como uma mudança ideológica dominante baseada na institucionalização e reconhecimento de claras demarcações etnorraciais, em vez da sua indefinição. No 
Brasil, tal tendência pode ser rastreada, pelo menos, a partir do final do século XX em diante.

De facto, durante os anos 90, as reivindicações políticas expressas pelos movimentos sociais que denunciavam a hegemonia branca e a discriminação racial ganharam maior impacto dentro da esfera política nacional. Para o censo de 1991, por exemplo, foi realizada uma campanha por ativistas e académicos sobre a questão do reconhecimento da categoria "negro" sob o lema "Não deixe sua cor passar em branco", exortando os brasileiros a assinalar uma cor mais escura no censo (Nobles, 2004 [2001]). Esse questionamento foi seguido pelo reconhecimento oficial da discriminação racial que levou o presidente Fernando Henrique Cardoso (FHC), ex-sociólogo das relações raciais, a receber uma delegação de ativistas e líderes sindicais por ocasião da marcha de Zumbi dos Palmares (um escravo fugitivo e figura icónica do movimento negro) contra o racismo. Nessa circunstância, a delegação apresentou um Plano Nacional contra o Racismo, onde se delineavam um conjunto de medidas para a população negra (Souza, 1996; Fry, 2000). Dando respaldo a esta iniciativa, o presidente nomeou um Grupo de Trabalho Interministerial para a Valorização da População Negra encarregado de desenvolver políticas públicas para a sua inclusão.

No I Programa Nacional de Direitos Humanos, formulado em 1996, um elenco de tais medidas surge definido, assim como a consequente necessidade de circunscrever institucionalmente o alvo dessas medidas. ${ }^{2} \mathrm{E}$ assim que a sugestão da ativista negra Dora Bertúlio ${ }^{3}$ para agregar todas as categorias não brancas em uma única categoria negro para ser usada nas estatísticas oficiais produzidas pelo IBGE (instituto nacional de estatística brasileiro) é adotada no programa.

O reconhecimento da desigualdade racial como uma característica estrutural da sociedade brasileira complementava assim a lógica de criminalização do racismo, consagrada anteriormente na Constituição de 1988 (artigo 5.o , XLII). ${ }^{4}$ Acrescentava ao seu enquadramento nos princípios liberais tradicionais de individualismo e universalismo na aplicação da justiça a promoção de uma determinada categoria social sub-representada em algum espaço institucional ou função (Feres Júnior e Campos, 2013). O seu caráter redistributivo, por oposição a uma lógica meramente judicialista, marca uma viragem no paradigma anterior na direção das ações afirmativas de cariz estatal, muito embora a própria Constituição já contivesse a possibilidade de estatuir nesse sentido.

É importante destacar a crescente organização de ativistas negros e o surgimento do Movimento Negro Unificado (MNU) na expressão deste reconhecimento.

2 Programa Nacional de Direitos Humanos (PNDH-1), Decreto-Lei n.. 1904, de 13 de maio de 1996, disponível em: http://dhnet.org.br/dados/pp/pndh/textointegral.html (consultado em 21/06/2011).

3 Esta sugestão foi aventada no Seminário Internacional sobre Multiculturalismo e Racismo: O Papel da "Ação Afirmativa" nos Estados Democráticos Contemporâneos. O seminário pretendeu reunir diretrizes para a formulação de políticas direcionadas especificamente para a população negra e é considerado por muitos como a ocasião inaugural das políticas de ação afirmativa (ver, inter alia, Costa, 2006).

4 O texto da Constituição afirma que "a prática do racismo constitui um crime imprescritível, sujeito à pena de prisão, nos termos da lei". 
A ideia de reversão das desigualdades com base étnica ou racial ganhara força desde pelo menos 1978, quando certas liberdades cívicas foram restauradas. Uma nova geração de ativistas e graduados universitários mudaram radicalmente a perceção que assentava na matriz culturalista e assimilacionista de outrora. ${ }^{5}$ Em 1983, o deputado Abdias do Nascimento, uma das principais figuras do movimento negro, apresentou ao Congresso o Projeto de Lei n. $\mathrm{o}$ 1332/1983, que estipulava propostas de tipo compensatório destinadas a promover a equidade entre negros e brancos em campos tão diversos como educação, acesso ao trabalho, remuneração e tratamento policial; o documento foi arquivado em 1989 (Jacoud, 2009). Como consequência das reivindicações cada vez mais audíveis do movimento negro, alguns governos regionais estabeleceram conselhos para apoiar a população negra, como o Conselho para a Participação e Desenvolvimento da Comunidade Negra do Estado de São Paulo (1984), cuja estrutura envolvia os líderes das maiores organizações negras da região. Esta primeira experiência foi seguida por outras, na Baía (1987), Rio Grande do Sul (1988) e Rio de Janeiro (1991), expandindo-se posteriormente para localidades menores.

Como observado por Guimarães (1999), a partir de 1985, com o retorno à democracia após 21 anos de ditadura, o estado procurou redefinir a sua relação com os movimentos sociais, incluindo o recém-formado MNU. Vários ativistas e militantes surgiram do ativismo comunitário (nas favelas, por exemplo), apoiados por organizações não governamentais. É o caso de Benedita da Silva, representante federal do Partido dos Trabalhadores (PT) e governadora do estado do Rio de Janeiro, cujas origens estão ligadas aos movimentos comunitários de base e cuja linha de ação política fundiu os temas centrais do PT com a agenda política do movimento negro. ${ }^{6}$ A agenda da igualdade racial foi prosseguida por deputados negros como Carlos Alberto Caó, Maria Benedita Pais e Paulo Paim, que vieram a propor o Estatuto de Igualdade Racial em 2006 (a ser aprovado em 2010). Em comum, compartilhavam a necessidade de implementar medidas de compensação para a população classificada como negra.

Em 2001, na Conferência Mundial contra o Racismo, em Durban, a delegação brasileira recebeu autorização presidencial (FHC) para defender a adoção de quotas raciais com vista à atenuação das desigualdades. ${ }^{7}$ Nas inúmeras reuniões preparatórias, quer domésticas quer internacionais, foi-se esboçando uma rede de ativismo negro discursivamente preparada para a litigância internacional em matéria de racismo e discriminação (Machado, 2004). Edna Roland, a representante brasileira, propôs nesta ocasião a adoção das medidas do grupo de trabalho interministerial, com especial destaque para a implementação de medidas positivas no

5 Sobre esta questão, ver as histórias autobiográficas contadas pelos indivíduos, reproduzidas em Verena Alberti e A. Pereira, História do Movimento Negro (2007).

6 Como ela mesma descreve em: Benedita Silva, "The Black Movement and political parties" (1999: 179-187).

7 Referido em: Amauri Pereira, "Um raio em céu azul: reflexões sobre a política de cotas e a identidade nacional brasileira" (2003: 463-482). 
trabalho e na saúde e o afinamento de metodologias de recolha de dados sobre populações afro-latinas. ${ }^{8}$

O período entre 1991 e 2003 foi de intensa atividade legislativa em relação à ação afirmativa, uma vez que a produção legislativa relativa a essa modalidade aumentou em mais de 90\%, e 24 ações afirmativas foram registadas nesse período (Jacoud, 2009). Em 2002 um decreto estabeleceu um programa de ação afirmativa no Serviço Público Federal, a ser observado por todos os órgãos da administração direta e indireta. ${ }^{9} \mathrm{O}$ programa é explícito no que diz respeito à consecução de metas percentuais de participação dos afrodescendentes em órgãos federais (artigo 2.. , I) e empresas contratadas por órgãos da administração pública federal (artigo 2.. $\left.{ }^{\circ}, \mathrm{IV}\right) .^{10}$

No entanto, foi sob a presidência de Lula da Silva, no cargo de 2003 até 2011, que as medidas consideradas durante o governo de FHC começaram a ser efetivadas. O mais significativo é a criação da SEPPIR em 2003 (Secretaria Especial de Políticas de Promoção da Igualdade Racial) e o estabelecimento do Sistema Nacional de Promoção da Igualdade Racial (Sinapir), uma rede de organizações públicas devotadas à eliminação da discriminação racial e da desigualdade ${ }^{11}$ Esses órgãos, que vão de secretarias municipais a conselhos de igualdade racial, efetivamente trouxeram o ativismo negro para perto do estado. O secretariado foi liderado pela primeira vez por Matilde Ribeiro, ativista e feminista do movimento negro e, posteriormente, em 2011, pela ministra Luiza Bairros, ${ }^{12}$ uma ex-militante do Movimento Negro Unificado, seguindo a tradição de nomear pessoas com filiação no movimento negro.

A SEPPIR teve por missão a coordenação nacional das medidas de igualdade racial. Três áreas foram escolhidas como prioritárias: educação, saúde e distribuição das terras de quilombo; em cada um destes vetores foram introduzidas medidas e políticas que consolidaram a lógica categorial aliada a uma preocupação com a reversão das desigualdades estruturais. As mudanças na educação incidiram na implementação do ensino de História e Cultura Africana e Afro-Brasileira em todas as escolas primárias e secundárias (Lei n.․ 10.639, de 09/01/2003) e na incorporação do programa ProUni, que concede bolsas de estudo para estudantes negros provenientes de escolas públicas para estudarem em universidades privadas. Em 2004 as primeiras quotas do ensino superior federal começaram a ser aplicadas. Entre as primeiras experiências com quotas para negros no ensino superior público e a sua implementação nacional sucederam-se um conjunto de iniciativas legais relativamente

8 Omar Thomaz Ribeiro e Sebastião do Nascimento, Entre a Intenção e o Gesto. A Conferência de Durban e a Elaboração de Uma Pauta de Demandas de Políticas Compensatórias no Brasil, São Paulo, NUPES, Universidade de São Paulo, 2003.

9 Programa Nacional de Ações Afirmativas, Decreto n. ${ }^{\circ}$ 4229, de 13/05/2002.

10 IPEA, Diretoria de Estudos Sociais, Instrumentos Normativos Federais Relacionados ao Preconceito e às Desigualdades Raciais - 1950-2003, Projeto BRA/01/013 PNUD, 2012.

11 O número de órgãos PIR ascendia em 2015 a sensivelmente mais de 300. Ver: Levantamento de Órgãos e Conselhos de Igualdade Racial para o SINAPIR, Secretaria de Políticas de Promoção de Igualdade Racial, Secretaria de Políticas de Promoção de Igualdade Racial, Governo Federal do Brasil, maio de 2015.

12 Luiza Bairros assumiu o cargo em 2011, durante o governo de Dilma Rousseff. 
à sua constitucionalidade. Por um lado, contou esta com a oposição de inúmeros alunos brancos que alegavam estar a ser discriminados; por outro, o processo instaurado em 2009 pelo Partido dos Democratas (DEM) contra a Universidade de Brasília por alegada violação de diversos princípios constitucionais ao admitir a raça como critério de seleção. Em 2012, o Supremo Tribunal Federal decidiu pela constitucionalidade da política de "cotas raciais", embora sustentasse a sua aplicação transitória. O presidente da Suprema Corte justificou esta decisão pela natureza histórica do preconceito e pelo facto de que "aqueles que não são afetados pelo preconceito de cor já estão em uma enorme vantagem".$^{13} \mathrm{O}$ sistema de quotas para negros disseminou-se rapidamente nas universidades públicas nacionais e, até 2015, 128 instituições de ensino federal implementaram a Lei n. ${ }^{\circ}$ 12.711, também conhecida como "Lei de Quotas". Finalmente, o Estatuto da Igualdade Racial, aprovado através da Lei n. ${ }^{\circ} 12.288$, de 20 de julho de $2010,{ }^{14}$ oferece uma definição operacional da população negra (artigo 1.ํ, IV), qual seja "o grupo de pessoas que se declaram preto ou pardo em resposta à questão da cor ou da raça", utilizada pelo IBGE. Assim, define um coletivo etnorracial que emerge como alvo de direitos. Como tal, uma política nacional para a saúde da população negra, por exemplo, é criada pelo Estatuto.

Mais recentemente a presidenta Dilma Rousseff sancionou em 2014 a Lei n.. 12.990, que institui quotas para negros no serviço público. Ficam reservadas $20 \%$ das vagas oferecidas nos concursos públicos federais para os autodeclarados "pretos" e "pardos". Segundo os dados da SEPPIR, no primeiro ano da sua aplicação teriam ingressado 638 indivíduos negros no serviço público.

Estes exemplos evidenciam que novos entendimentos coletivos sobre os limites grupais estão a emergir sustentados por atores institucionais. Todavia, sem a mudança na perceção dos quadros culturais que definiam os lugares diferenciados das categorias sociais essa institucionalização não se teria dado. A politização das categorias etnorraciais impulsionadas por reivindicações dos ativistas negros e a estratégia de apropriação social ${ }^{15}$ resultante da sua incorporação nas estruturas estatais reposicionou com sucesso fronteiras etnorraciais. Simultaneamente, perturbou o consenso anterior sobre o significado e a localização desses limites.

\section{Pluralidade de repertórios e ressignificação identitária}

A natureza frágil do compromisso sobre as fronteiras dos grupos foi revelada na controvérsia em torno das quotas raciais no sistema educacional. Através de

13 Retirado de: http://www.brasil.gov.br/noticias/arquivos/2012/04/26/cotas-raciais- sao-constitucionais diz-stf (consultado em 12/05/2012).

14 A Lei n.. 12.288 , de 20 de julho de 2010, institui o Estatuto da Igualdade Racial e altera as Leis n..$^{\circ} 7716$, de 5 de janeiro de 1989, n. .9029 , de 13 de abril de 1995, n. .7347 , de 24 de julho de 1985, e n. ${ }^{\circ} 10.778$, de 24 de novembro de 2003.

15 O termo a é retirado de McAdam, Tarrow e Tilly (2004) e refere-se a mecanismos que permitem que populações oprimidas ou pobres em recursos superem as suas lacunas organizacionais. 
entrevistas com pessoas envolvidas nesta discussão, bem como atores privilegiados na estratégia de implementação das novas medidas, procurámos delinear a organização temática destes discursos ressaltando os temas mais estruturantes nas justificações e perspetivas sobre as categorizações etnorraciais que estes atores connosco partilharam. É esta dimensão avaliativa, relacionada com entendimentos culturais da pertença grupal, que se encontra inerente à ideia de repertório. Os discursos destes atores revelam diversos repertórios aos quais os mesmos recorrem para definir culturalmente que categorizações devem ser reconhecidas e às quais os próprios aderem. Seguindo uma estratégia indutiva, destacamos três repertórios que surgem demarcados pela análise de conteúdo temática, seguidos de uma breve explicação da sua estrutura. A classificação dos repertórios é o resultado da análise do conjunto de entrevistas recolhidas durante o trabalho de campo no Rio de Janeiro, na Baía de Todos os Santos e em Florianópolis. A este acervo devem somar-se os documentos consultados, que vão desde legislação e peças jornalísticas a textos na blogosfera que, embora não tenham sido considerados para análise com o MaxQDA, reforçaram a construção dos principais traços dos repertórios. Um aspeto metodológico que importa referir prende-se com a opção de não tomar a autoidentificação como um princípio de compreensão dos posicionamentos sociais. Esse trabalho, feito sobretudo por Silva e Reis (2012), não constitui a orientação aqui tomada. Neste sentido, o guião de entrevista que serve de base à análise preocupou-se em considerar os entendimentos dos entrevistados sobre os significados das categorizações etnorraciais usadas socialmente, quer no domínio do quotidiano quer no institucional. Foi assim dividido em três partes que correspondem a três vetores analíticos. Concretamente: o institucional, contemplando as configurações organizacionais e de poder e os regimes legais; o simbólico, onde se inserem questões da ordem das identidades e identificações, tais como os espaços das identificações (nacional ou grupal), e a reformulação ou institucionalização das categorias identificatórias; e o político, onde incluímos questões sobre modelos de gestão da diversidade, o significado da (e adesão à) ideia de multirracialidade, ou de políticas diferencialistas.

O primeiro aspeto a assinalar é que o resultado das análises efetuadas com o MaxQDA expressa claramente três repertórios distintos (ver figura 1). Estas três combinações são obtidas através da matriz de códigos que mostra quantos segmentos são atribuídos a determinados documentos. O nosso corpus é constituído por 1629 unidades temáticas extraídas de 25 documentos (entrevistas semidiretivas). Esta é uma mera representação gráfica não evidenciando nenhuma associação estatística. Permite, no entanto, ver que grupos podem ser estabelecidos na medida em que determinados entrevistados partilham clusters de temas.

Um primeiro repertório, que designamos diluição (seguindo a noção de Alba de blurring e a sua reformulação por Wimmer), agrega os temas da mistura, associados que estão a uma perceção de um ethos nacional particular - o excepcionalismo brasileiro. Estes entrevistados insistem na permanência e efetividade de um tal ethos, atribuindo um lugar preponderante deste tema na organização dos seus sistemas de significado. A mestiçagem, o Brasil país de mistura, bem assim como a noção de um racismo "à brasileira" que se dilui nos encontros quotidianos, pontua a 


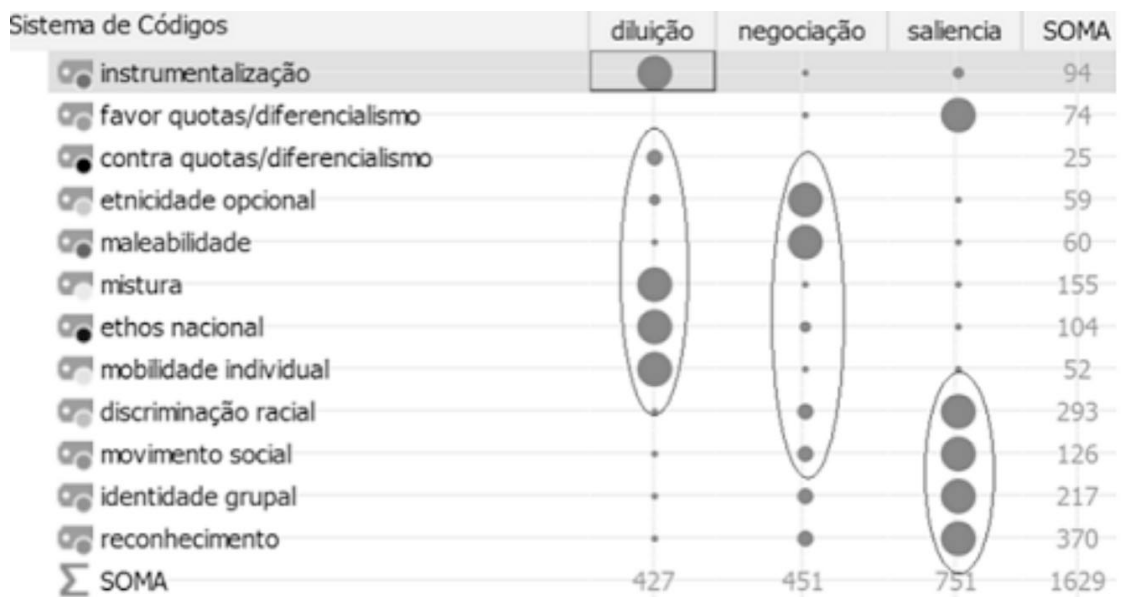

Figura 1 Matriz de códigos

adesão a um tal ethos. Ele expressa o repertório hegemónico até ao momento, dentro das restrições simbólicas e institucionais sobre a narrativa nacional da miscigenação. Esta preponderância da identidade nacional é referida por um dos entrevistados da seguinte forma:

Mas há outras maneiras de imaginar o Brasil: você pode dizer, por exemplo, que é um país de fusão, de várias populações, não há necessidade de "raça". Essa ideia de fusão é a velha ideia que está sendo fortemente rejeitada. Mas isso fazia parte da mentalidade dos cidadãos. [Ent. 13, académico]

Este discurso postula a importância da diluição das fronteiras etnorraciais como uma dinâmica social inerente à sociedade brasileira. A insistência no caráter híbrido da sociedade brasileira, quer no plano das representações da coesão nacional e da importância desta, quer nos seus reflexos quotidianos, onde a proximidade, ao invés da distância social lhe é consubstancial, marca em larga medida as prioridades deste repertório. Mesmo que os entrevistados aceitem a existência de discriminação, o perigo de uma quebra ou mesmo fragmentação desta harmonia social é visto como iminente caso se dê espaço a reivindicações identitárias que colidam com esta matriz. A oposição à ação afirmativa é sustentada com base na ideia de que a racialização é um fenómeno estranho à sociedade brasileira. A mistura social e cultural é o núcleo inquestionável na forma cognitiva de adesão ao ethos nacional, associação bem representada no manifesto antiquotas endossado por várias personalidades públicas em 2008:

a nação brasileira elaborou uma identidade amparada na ideia antirracista de mestiçagem e produziu leis que criminalizam o racismo. [...] A condição subterrânea do 
preconceito é um atestado de que há algo de muito positivo na identidade nacional brasileira, não uma prova de nosso fracasso histórico. [...] A fabricação de raças oficiais e a distribuição seletiva de privilégios segundo rótulos de raça [...] representaria uma revisão radical de nossa identidade nacional e a renúncia à utopia possível da universalização da cidadania efetiva. Ao julgar as cotas raciais, o STF não estará deliberando sobre um método de ingresso nas universidades, mas sobre o significado da nação. ${ }^{16}$

Este repertório estabelece a continuidade entre mistura étnica e racial e o princípio da cidadania. Assim, o hibridismo é também o espaço simbólico para a integração social e, em última análise, relaciona-se com uma partilha essencialista do mesmo ethos que torna ineficaz ou perigosa toda a diferenciação etnorracial. Ao contrário da saliência deste tipo de adesões, estes entrevistados julgam que a cidadania se alicerça na supressão de tais identidades. O excerto abaixo evidencia a crença numa sociedade de mistura e o receio de que essa constante antropológica seja perturbada caso se inscrevam identidades etnorraciais na esfera pública e do estado.

[...] como é que é essa população brasileira, e como é que ela se percebe, como é que ela se vêe tal. Enfim, não sei como é que isso vai mudar... E com isso se perde uma coisa [...] que alguns acham que é um mito, mas que é uma coisa efetivamente real, que é a miscigenação nesse país. Entendeu? Tem todas as complicações do mundo, tem todos os senões, isso aí,... alguma mistura há que ser considerada nesse país: as pessoas aqui são misturadas, e são mesmo, entendeu? [Ent. 12, académica]

Para estes entrevistados, a raça não é um fator proeminente na explicação da desigualdade. Como em pesquisas que revelaram a diferença entre explicações individualistas e estruturais da desigualdade racial (Bobo e Kluegel, 1993) a relação entre estrutura e raça é minimizada, enquanto os fatores baseados na classe são sublinhados. A pobreza torna-se a explicação preferida como um proxy social para as diferenças entre categorias etnoculturais. No entanto, isto é enquadrado em termos muito além das considerações tradicionais sobre a mistura social (ou a prática do social mixing). Um ex-responsável por um organismo do estado refere-se à perversidade do sistema de cotas da seguinte forma:

E não precisa aí na verdade de um sistema de proteção... Na verdade está toda aí uma população que já conseguiu uma posição bastante boa porque conseguiu superar uma série de barreiras que a maior parte da população não conseguiu. Mas essa população, eu acho que ela deveria disputar o lugar dela na sociedade com os outros, não deveria ser privilegiado, como um grupo especial. [Ent. 15 , ex-responsável estatal]

Embora não reproduza inteiramente um tipo de explicação individualista, a coincidência entre categoria racial e posicionamento estrutural não é referida por estes 
atores. Estes discursos não atribuem uma centralidade à desigualdade racial ou à discriminação, preferindo salientar fatores como a pobreza e a mobilidade individual.

Para estes atores, a mistura racial é o quadro significativo através do qual as relações etnorraciais são concebidas. O quadro pressupõe a imbricação de características socioculturais e biológicas. Neste sentido, ele faz uso do velho roteiro ideológico da democracia racial como um recurso simbólico. Como é sabido, a ideia de "democracia racial" foi articulada pela antropologia social de Freyre da sociedade brasileira (Freyre, 1945, 1960). Através dela, Freyre postula um continuum socioantropológico entre mistura racial - "mestiçagem" - e estabilidade social. Contrariamente à realidade da divisão racial nos Estados Unidos, no Brasil a assimilação era algo que emergia naturalmente sem apoio estatal. O Brasil "inventou" um paradigma cultural e político de interpenetração etnorracial onde a discriminação, ainda que existente, não poderia culminar em conflito social. No entanto, mesmo se as pessoas que entrevistei não endossam plenamente esta narrativa, reconhecendo em alguns casos a distância entre o que esta presume e a realidade social, elas argumentam de acordo com os mesmos princípios morais e antropológicos que a estruturam. Consequentemente, os entrevistados que se baseiam fortemente nessa construção simbólica foram os que se opuseram mais enfaticamente às ações afirmativas.

O segundo repertório a que faremos referência é o da negociação. Neste caso os temas mais estruturantes do sistema de significados que os indivíduos usam para entender a formação de fronteiras etnorraciais são a etnicidade opcional, a maleabilidade dos limites etnorraciais e a discriminação/desigualdade racial. Apesar de não ser tão representativo no discurso destes entrevistados, o ethos nacional como recurso cultural continua a ser considerado operativo. Neste sentido, apesar do reconhecimento das estruturas de desigualdade racial, o mito da mistura como valor cultural e biológico tem implicações normativas, como argumenta um entrevistado:

A construção da nacionalidade continua a ser uma nacionalidade baseada na miscigenação. [...] De certa forma, fenómenos como o direito indígena, o reconhecimento do quilombo, etc. põem em questão a ideia de uma identidade nacional homogeneizadora. E a discriminação racial, bem como, como é evidente, esse mito é questionado. Mas acho que ainda tem valor; ele continua a servir como um marco regulatório para as relações sociais. [Ent. 14 académico)

Reconhecer a importância do ethos nacional é consequente para a fluidez das fronteiras etnorraciais, algo que estes entrevistados sublinham. Desse ponto de vista, considerar a natureza negociável das identidades implica tanto rejeitar a versão essencialista da identidade nacional como desessencializar pertenças abrangentes a grupos específicos. Este raciocínio quadra com a definição de etnicidade opcional (Waters, 1990) e relaciona-se com a transição ontológica de identidades para identificações. Em contraste com o repertório seguinte, os entrevistados consideram que as categorizações etnorraciais não são fixas e os indivíduos podem escolher os aspetos que lhes são mais apelativos. 
Para mim negro é uma categoria de identidade racial... Isso quer dizer que a pessoa não necessariamente tenha que ter rasgos físicos, a pessoa pode não ser percebida como negro, mas a pessoa pode-se identificar como negro, do ponto de vista político-ideológico, por resgatar uma ancestralidade real ou mítica, né, mas a identidade racial é construída como uma constelação de elementos que cada pessoa constrói... [Ent. 8, responsável estatal]

Faz parte deste quadro insistir na maleabilidade das identificações (que deixam de ser identidades), mesmo que, ou por causa de, condicionadas por fenómenos históricos e sociais. É uma tal historicidade assinalada por estes entrevistados que admite a pluralidade das identificações. Afirmar-se como "negro", deixa de ter valor ontológico, como veremos no caso da saliência, e é perspetivado como uma opção num jogo de opções:

Bem a questão é que o discurso se constrói um pouco por polaridades. Se efetivamente um grupo na sociedade se constrói como branco outro tem que se construir como negro. Aí sim há um risco de racialização. Não obstante eu acho que se não tomarmos discursos isolados, mas tomarmos a dinâmica de construção do espaço público, o que nós percebemos é que há uma esfera pública, um debate público muito dinâmico que reconstrói e desconstrói racializações. [Ent. 14, académico]

Contrariamente aos entrevistados anteriores, a discriminação é sistematicamente salientada. A desigualdade racial é, para todos os efeitos, uma variável estrutural que impõe uma hierarquia à ordem social das identificações; melhor dizendo, cristaliza certas categorias em lugares sociais predefinidos antes mesmo da possibilidade quotidiana da negociação resultante da diversidade de contextos sociais. É neste sentido que os atores que partilham este repertório aceitam a inscrição de categorias racializadas na esfera pública e do estado.

Em suma, embora os limites possam ser negociados e as adesões etnorraciais tenham uma margem de escolha, a estrutura racializada da sociedade brasileira faz com que certas categorias sejam socialmente impostas. Todavia, a um nível mais empírico, a interseção de outras categorias é passível de reforçar ou mitigar esse fenómeno. É justamente na pluralidade de adesões que este discurso coloca a ênfase. Contrariamente ao anterior, nenhuma adesão prepondera nem esta tem um reflexo ontológico que dá significado ao lugar ocupado no mundo social. Por exemplo, a categoria negro é entendida como política e simbólica, e como tal mobilizada como uma metáfora para reivindicações públicas.

Finalmente, o terceiro repertório que designamos saliência organiza-se em torno dos seguintes temas: identidade grupal (os entrevistados enfatizam as origens ou raízes africanas e a necessária consideração do grupo negro, defendendo ainda a reformulação crítica do ethos nacional); discriminação racial (o discurso enfatiza as diversas instâncias de discriminação, mas sobretudo a desigualdade estrutural entre negros e brancos); reconhecimento, (os entrevistados insistem na importância do fenótipo como marca de categorização, reivindicam uma consciência étnica, e aludem a uma identidade racial estigmatizada que necessita de ser positivada); movimento 
social (contributos positivos do movimento social, ou afinidade com o movimento social). Quanto a este último aspeto, convirá notar que os entrevistados colocam a ênfase no papel da sociedade civil organizada no sentido da modificação dos processos identificatórios. Isto torna-se particularmente relevante quando contrastado com a ideia de instrumentalização (do primeiro repertório) por parte do estado e dos movimentos sociais, no sentido de um oportunismo classificatório. Como este aspeto diferencia de facto duas posturas relativamente à bondade ética do diferencialismo ele sinaliza um juízo moral sobre a política de identidade.

A reivindicação de uma consciência étnica articula-se no discurso destes entrevistados com a crítica ao paradigma nacional do hibridismo, da mistura, e das suas fundações na ideologia da "democracia racial". Como principais princípios de organização, este repertório coloca a ênfase na operacionalidade e proeminência das fronteiras etnorraciais, valorizando a assunção de uma "consciência étnica". Neste repertório, a identidade de um grupo específico (o negro) assume um lugar central no discurso dos entrevistados. Sendo certo que a maioria destes entrevistados se encontrava, de forma mais ou menos intensa, implicada no movimento social, alguns identificam-se como brancos. Os atores rejeitam as definições tradicionais da excecionalidade da cultura brasileira. Assim, a mistura não enquadra mais os entendimentos sociais das relações raciais nem da unidade nacional. Ao invés, o racismo, a desigualdade racial e a subordinação histórica dos negros constituem a narrativa central que marginaliza a interpretação culturalista; ou seja, os atributos culturais imputados à nação deixam de assegurar a unidade simbólica. Na medida em que o "lugar do negro" se torna crucial, para esta narrativa coletiva ser apropriada de forma igualitária é imprescindível reformulá-la. A ligação entre a ressignificação da história nacional e as reivindicações de identidade negra é abordada no seguinte trecho:

Nós que viemos para cá na condição de escravo, perdemos essa memória... então o que nos deixa vivo é justamente imaginar e reconhecer que nós viemos de lá, senão enlouqueceríamos, porque foi muito violento [...] somos africanos fora da África, porque saímos de lá numa situação extremamente violenta, permaneceu-se nessa situação violenta e... como eu posso dizer, para nós o que nos alimenta é beber nesses valores. [Ent. 11, académica e ativista]

Assim, o fortalecimento das fronteiras ganha uma forma coletiva simbólica que supera (uma identidade transfronteiriça) o vínculo nacional. Esta forma é aquela que incorpora uma posição social muito específica, mediada pela etnia que, em termos práticos, se traduz na necessidade de autoidentificação racial, ou seja, ganhar "consciência étnica". Como diz Nilma Bentes, do Movimento Negro Unificado, não é suficiente ser consciente de sua cor, "é preciso ter uma perceção aguda de pertencer a um povo subjugado e explorado no passado e no presente" ${ }^{17}$ Um entrevistado formula essa conceção da seguinte maneira:

17 Citado em Verena Alberti e A. A. Pereira, História do Movimento Negro (2007: 526). 


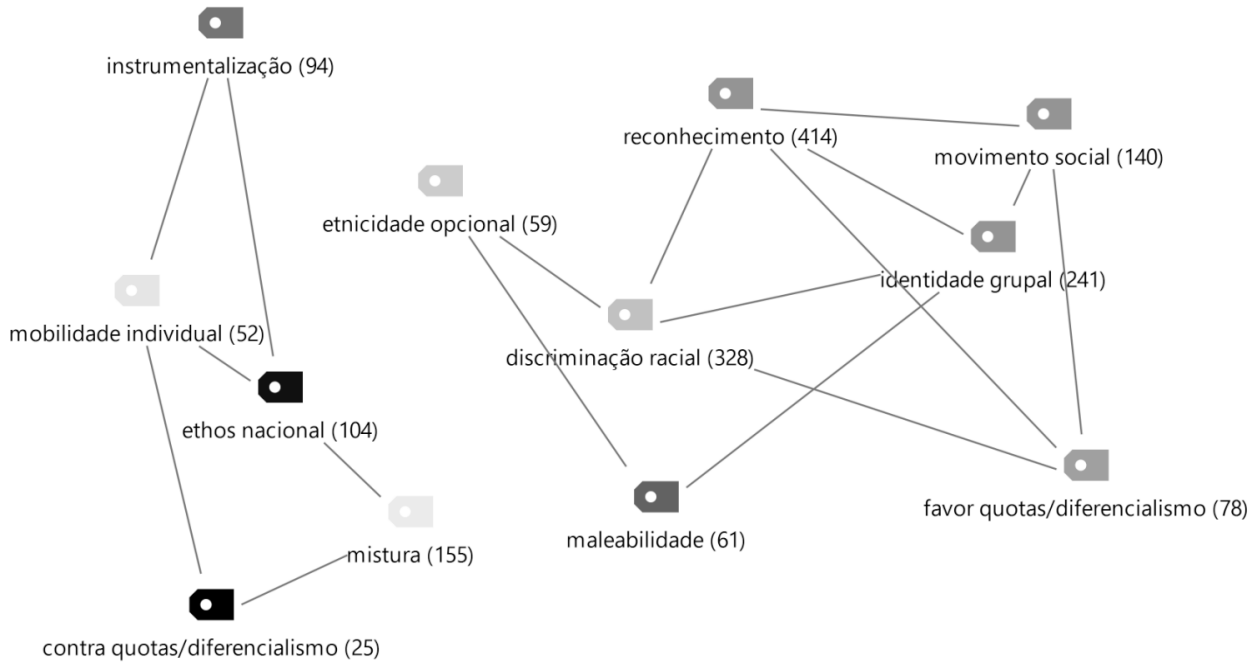

Figura 2 Modelo de coocorrência de códigos

\begin{abstract}
É, há uma coisa muito importante nessa questão da consciência negra, que é fundamental que é você se assumir como negro. Porque é tão difícil ser negro no Brasil... [...] E é uma das coisas que a gente chama de consciência negra, que é reconhecer que se é negro, é não se envergonhar de ser negro, é não tentar embranquecer, como aconteceu comigo na minha adolescência. [Ent. 18, responsável estatal].
\end{abstract}

Para estes indivíduos a sociedade é estruturada por linhas raciais que afetam o estatuto social do indivíduo e as suas trajetórias. Neste sentido, para estes atores as condições estruturais não são superadas por uma, mesmo que imaginada, condição cultural abrangente que postula a mistura como "um filtro [cultural] através do qual os indivíduos avaliam a sua identidade racial" (Silva e Reis, 2012: 396). Em contraste, a compreensão das fronteiras etnorraciais enfatiza a sobreposição entre categorização racial e estrutura social. É por esta coincidência que a identificação racial se torna saliente, contrariamente a um quadro (de democracia racial) que enfatiza as relações sociais diárias como contextos sociais não problemáticos. Uma conceção desta natureza implica a negação (ou a reformulação) de uma versão hegemónica da identidade nacional. Mesmo que alicerçada numa motivação política, para estes atores as fronteiras entre os grupos etnorraciais pretendem-se reforçadas: "tornar-se negro", como um entrevistado menciona, equivale a "não se deixar embranquecer". Paradoxalmente, contra a reinterpretação do continuum cultural e histórico simbolizado no ethos nacional, a maioria dos entrevistados que mobiliza este repertório, insiste numa condição trans-histórica que une um coletivo por uma experiência compartilhada de subjugação. 
A figura 2 mostra uma representação gráfica das relações entre os diferentes códigos (temas) e as associações que eles compõem. Ela distingue os três repertórios antes examinados na sua relação temática. Trata-se de uma representação gráfica que não tem leitura estatística.

\section{Conclusão}

Ficou patente que os repertórios analisados, bem para além de uma discussão sobre os méritos ou deméritos das ações afirmativas, revelam três formas de pensar as categorizações etnorraciais e, consequentemente, as fronteiras das identidades coletivas. Assim sendo, o que se pretendeu efetuar neste artigo foi considerar uma questão social polémica para, através dela, perceber as modalidades de construção de fronteiras etnorraciais admitidas pelos atores. A acentuação e difusão de semânticas étnicas ou raciais na esfera do estado - em que as classificações etnorraciais surgem como princípios de distribuição de bens materiais e simbólicos - tem implicado uma reformulação do paradigma nacional brasileiro. Bouchard (2011) referiu-se ao imaginário coletivo brasileiro como de "mesclagem" (mixité), e Silva e Reis (2012) sustenta que a mistura é o "filtro cultural" que avalia as relações raciais. A simples assunção da necessidade de ação afirmativa para emancipar uma dada categoria social cujos contornos são etnorraciais coloca em causa a aceitação esquemática de um tal paradigma. Esta visão surge, assim, demasiado escorreita e colide com o que surge claramente como uma reconfiguração das interpretações culturais, bem assim como das adesões por estas suscitadas.

Uma situação de desencontro entre cultura e agencialidades provoca, como sugerido por Swidler, o surgimento de narrativas conflituais ou concorrentes. Os repertórios aqui analisados indicam três formas de perceber as fronteiras etnorraciais, que se explicam pela influência relativa das mudanças culturais e institucionais. E indicam também o fragmentar do imaginário coletivo e dos seus alicerces tradicionais. Da diluição promovida pelo ethos nacional, onde os limites da solidariedade social são circunscritos pela história específica da nação brasileira, à saliência de novas fronteiras nas opções estratégicas dos movimentos sociais e correspondente revisão crítica desse mesmo ethos, passando pela negociação das identificações etnorraciais e o alargamento do seu espaço - estes três quadros cognitivos exemplificam maneiras de pensar as categorizações e as estruturas simbólicas de significado que as constroem. Apesar da crítica cosmopolita ou transnacional dos significados nacionais, continua a ser importante reconhecer o poder estruturante dessas narrativas na compreensão dos modos como a diversidade étnica e racial é perspetivada. As mudanças políticas e institucionais brevemente descritas devem ser entendidas tendo como pano de fundo mudanças fundamentais nos quadros para as fronteiras coletivas e identificações simbólicas. A relevância de uma identidade negra é parcialmente explicada pelo processo político que levou à incorporação de uma categoria negra nos scripts das organizações estatais. Estas dinâmicas são interdependentes das visões da elite sobre os limites da organização social da diferença e das codificações de pertença. A incorporação das elites negras nas estruturas estatais e a política concertada 
que o estado seguiu para uma maior justiça racial encarnam uma estratégia de apropriação social, dando simultaneamente origem à redefinição das classificações hegemónicas de identidade.

\section{Referências bibliográficas}

Alba, R. (1990), Ethnicity in America. The Transformation of White Ethnicity, New Haven, Yale University Press.

Alberti, Verena, e A. Pereira (2007), História do Movimento Negro, Rio de Janeiro, Fundação Getulio Vargas.

Bailey, Stanley R., F. Fialho, e M. Peria (2015), “Support for race-targeted affirmative action in Brazil", Ethnicities, 0 (0) pp. 1-34.

Barth, Fredrik (1969), "Introduction”, em Fredrik Barth (org.), Ethnic Groups and Boundaries. The Social Organization of Cultural Difference, Londres, Allen \& Unwin, pp. 9-38.

Bobo, Lawrence, e J. Kluegel (1993), “Opposition to race-targeting: self-interest, stratification ideology, or racial attitudes?", American Sociological Review, 58, pp. 443-464.

Bouchard, Gerard (2011), “What is interculturalism?”, McGill Law Journal, 56 (2), pp. 435-468.

Brubaker, Rogers (2004), Ethnicity without Groups, Cambridge, MA, Harvard University Press.

Campbell, John L. (2004), Institutional Change and Globalization, Princeton, Princeton University Press.

Costa, Sérgio (2006), Os Dois Atlânticos. Teoria Social, Antirracismo, Cosmopolitismo, Belo Horizonte, Editora UFMG.

Eisenstadt, S. N. (2002), “The construction of collective identities and the continual reconstruction of primordiality", em S. Malesevic e Mark Haugard (orgs.), Making Sense of Collectivity. Ethnicity, Nationalism and Globalisation, Londres, Pluto Press, pp. 33-87.

Feres Júnior, João, e Luiz Augusto Campos (2013), “Liberalismo igualitário e ação afirmativa: da teoria moral à política pública", Revista de Sociologia e Política, 21 (48), pp. 85-99, https://dx.doi.org/10.1590/S0104-44782013000400005

Freyre, Gilberto (1945), Brasil. An Interpretation, Nova Iorque, Alfred A. Knoff.

Freyre, Gilberto (1960), Brasis, Brasil, Brasília, Lisboa, Livros do Brasil.

Fry, Peter (2000), "Politics, nationality and the meanings of 'race' in Brazil", Daedalus, 129 (2), pp. 83-118.

Gross, C. (2012), Políticas de la Etnicidad. Identidad, Estado y Modernidad, Bogotá, Instituto Colombiano de Antropologia y Historia.

Guimarães, A. S. (1999), Racismo e Antirracismo no Brasil, São Paulo, Editora 34.

Hasenbalg, Carlos (1979), Discriminação e Desigualdades Raciais no Brasil, Rio de Janeiro, Graal. Jaccoud, L. (2009), A Construção de Uma Política de Promoção da Igualdade Racial. Uma Análise dos Últimos 20 Anos, Brasília, IPEA.

Lamont, Michèle (1995), “National identity and national boundary patterns in France and the United States", French Historical Studies, 19 (2), pp. 349-365. 
Lamont, Michèle (2000a), The Dignity of Working Men. Morality and the Boundaries of Race, Class, and Citizenship, Cambridge, MA, Harvard University Press, e Nova Iorque, Russell Sage Foundation.

Lamont, Michèle (2000b), “The rhetoric's of racism and anti-racism in France and the United States", em Michèle Lamont e Laurent Thévenot (orgs.), Rethinking Comparative Cultural Sociology. Repertoires of Evaluation in France and the United States, Cambridge, UK, Cambridge University Press, pp. 25-55.

Lamont, Michèle, e Nizam Mizrachi (2011), “Ordinary people doing extraordinary things: responses to stigmatization in comparative perspective", Ethnic and Racial Studies, 35 (3), pp. 365-381.

Linz, Juan, e A. Stepan (1996), Problems of Democratic Transition and Consolidation. Southern Europe, South America and Post-Communist Europe, Baltimore, Johns Hopkins University Press.

Loveman, Mara (1999), “Comment: is 'race' essential?", American Sociological Review, 64, pp. 891-898.

Loveman, Mara (2014), National Colors. Racial Classification and the State in Latin America, Nova Iorque, Oxford University Press.

Loveman, Mara, J. O. Muniz, e S. R. Bailey (2011), “Brazil in black and white? Race categories, the census, and the study of inequality", Ethnic and Racial Studies, 35 (8), pp. 1466-1483.

Machado, E. P. (2004), Desigualdades Raciais e Ensino Superior. Um Estudo sobre a Introdução das "Leis de Reserva de Vagas para Egressos de Escolas Públicas e Cotas para Negros, Pardos e Carentes" na Universidade do Estado do Rio de Janeiro (2000-2004), Rio de Janeiro, tese de doutorado de Antropologia e Sociologia do IFCS da UFRJ.

Mattos, Hebbe (2005), "Repairing the past: confronting the legacies of slavery, genocide, \& caste", em Proceedings of the Seventh Annual Gilder Lehrman Center International Conference, New Haven, Yale University.

McAdam, Douglas, Sidney Tarrow, e Charles Tilly (2004), Dynamics of Contention, Cambridge, UK, Cambridge University Press.

Mouzelis, Nicos (2008), Modern and Postmodern Social Theorizing. Bridging the Divide, Cambridge, UK, Cambridge University Press.

Nobles, Melissa (2004 [2001]), “Racial categorization and censuses”, em David I. Kertzer e Dominique Arel (orgs.), Census and Identity, Cambridge, UK, Cambridge University Press, pp. 43-70.

Pereira, Amauri (2003), “Um raio em céu azul: reflexões sobre a política de cotas e a identidade nacional brasileira", Estudos Afro-Asiáticos, 25 (3), pp. 463-482.

Sansone, Livio (1996), “Nem somente preto ou negro: o sistema de classificação da cor no Brasil que muda", Afro-Asia, 18, pp. 165-188.

Silva, Benedita (1999), “The Black Movement and political parties”, em Michael Hanchard (org.), Racial Politics in Contemporary Brazil, Durham e Londres, Duke University Press, pp. 179-187.

Silva, G. M. (2016), “After racial democracy: contemporary puzzles in race relations in Brazil, Latin America and beyond from a boundaries perspective", Current Sociology, 64 (5), pp. 794-812, DOI: 10.1177/0011392115590488 
Silva, G. Moraes, e Elisa P. Reis (2012) “The multiple dimensions of racial mixture in Rio de Janeiro, Brazil: from whitening to Brazilian negritude", Ethnic and Racial Studies, 35 (3), pp. 382-399, DOI: 10.1080/01419870.2011.589524.

Song, Miri (2003), Choosing Ethnic Identity, Cambridge, UK, Polity Press.

Souza, Jezé (org.) (1996), Multiculturalismo e Racismo. O Papel da Ação Afirmativa nos Estados Democráticos Contemporâneos, Brasília, Ministério da Justiça.

Swidler, Ann (1986), "Culture in action: symbols and strategies", American Sociological Review, 51 (2), pp. 273-286.

Tilly, Charles (1978), From Mobilization to Revolution, Reading, MA, Addison-Wesley.

Touraine, Alain (1988), La Parole et le Sang. Politique et Societé en Amérique Latine, Paris, Odile Jacob.

Valle Silva, Nelson do (1985), "Updating the cost of not being white in Brazil”, em P. M. Fontaine (org.), Race, Class and Power in Brazil, Los Angeles, UCLA Center for Afro-American Studies, pp. 42-55.

Wallman, Sandra (1978), "Boundaries of 'race': processes of ethnicity in England", Man, 13 , pp. $200-217$.

Waters, Mary C. (1990), Ethnic Options. Choosing Identities in America, Berkeley, University of California Press.

Wimmer, Andreas (2008), “The making and unmaking of ethnic boundaries: a multilevel process theory", AJS, 113 (4), pp. 970-1022.

Wimmer, Andreas (2013), Ethnic Boundary Making. Institutions, Power, Networks, Oxford, Oxford University Press.

Wood Charles, e J. A. M. Carvalho (1988), The Demography of Inequality in Brazil, Cambridge, UK, e Nova Iorque, Cambridge University Press.

Nuno Oliveira. Pós-doutorando no Instituto Universitário de Lisboa (ISCTE-IUL), Centro de Investigação e Estudos de Sociologia (CIES-IUL), Lisboa, Portugal.

E-mail: filicastrol@gmail.com

Receção: 18 de dezembro de 2015 Aprovação: 13 de fevereiro de 2017 